\title{
A Spreadsheet-Based Model Demonstrating the Nonuniform Economic Effects of Varying Reproductive Performance in Ohio Dairy Herds
}

\author{
C. Meadows, P. J. Rajala-Schultz, and G. S. Frazer \\ Department of Veterinary Preventive Medicine, The Ohio State University, Columbus 43210
}

\section{ABSTRACT}

A spreadsheet-based model was developed to estimate the economic effect of varying reproductive performance in dairy herds. Scenarios were created to model an average cow with respect to production, herd lifetime, and reproductive events. Average milk yield per day of life as well as lifetime calf and replacement heifer production were examined. Additional inputs representing milk, feed, semen, calf, and salvage prices were used to calculate net cash flow for each day of herd life for the average cow in a scenario. Economic comparison of different scenarios was accomplished using an equivalent annual cash flow (annuity) methodology.

Herd performance measures and prices representative of Ohio dairy herds were used to establish a baseline average cow that had a $160-d$ calving-to-conception interval [days open (DO)]. Alternative scenarios that differed from baseline in $\mathrm{DO}$, annual culling rate, and feed and milk prices were created to characterize the effects of changes. Under scenario inputs representative of typical Ohio dairy herds, the model indicated that a lower annual culling rate $(25 \%)$ was preferable to higher annual culling rates ( 34 or $45 \%$ ). The model estimated maximum average milk yield per day of life to occur at 110 DO. At 34\% annual culling rate, calves and replacement heifers produced per lifetime declined as DO increased; beyond $150 \mathrm{DO}$, the modeled cow produced less than 1 replacement heifer per lifetime. The model also estimated a loss of $\$ 1.37$ per cow per year for a 1-d increase in DO beyond $160 \mathrm{~d}$. At $20 \%$ higher feed and milk prices, the model estimated a loss of $\$ 1.52$ per cow per year; at $20 \%$ lower feed and milk prices, the model estimated a loss of $\$ 1.23$ per cow per year. Furthermore, the model suggested that the loss associated with a 1-d increase in DO changed as DO changed. Using baseline inputs, the model calculated losses for a 1 -d increase of $\$ 0.44$ per cow per year at $130 \mathrm{DO}$ and $\$ 1.71$ per cow per year at 190 DO. The nonuniform

Received July 1, 2004.

Accepted December 7, 2004.

Corresponding author: Cheyney Meadows; e-mail: meadows. 27@osu.edu. nature of the cost of additional DO is important to veterinarians and producers. The implication is that inefficient reproduction becomes marginally more costly to producers as performance declines and warrants increased attention. Conversely, marginal benefits of improved reproduction decrease as performance improves. Herds with strong reproductive performance have less opportunity to capture economic benefits of improvement.

(Key words: reproduction, days open, equivalent annual cash flow)

Abbreviation key: $\mathbf{C I}=$ calving interval, $\mathbf{C R}=$ conception rate, $\mathbf{D F S}=$ days to first service, $\mathbf{D O}=$ days open, $\mathbf{E A C}=$ equivalent annual cash flow, $\mathbf{E D C}=$ equivalent daily cash flow, $\mathbf{E D R}=$ estrus-detection rate, $\mathbf{F S C R}=$ first-service conception rate, $\mathbf{I E}=$ insemination expense, $\mathbf{N P V}=$ net present value, $\mathbf{P R}=$ pregnancy rate, SPcow $=$ services per cow .

\section{INTRODUCTION}

It is widely accepted that suboptimal reproductive performance represents financial losses to dairy producers, and that improving reproduction should improve profitability of dairy farms (Schmidt, 1989; Plaizier et al., 1997). As reproductive performance declines, economic returns can be affected by reduced milk yield per cow per day of herd life, increased culling for reproductive reasons, fewer available replacement heifers, increased semen usage, and added costs of veterinary interventions (Britt, 1985).

Numerous reproductive indices reported in summaries offered by Dairy Herd Improvement (DHI) organizations may be monitored in dairy herds (Fetrow et al., 1990). A very useful summary measure is the calvingto-conception interval or days open (DO) for the herd. Days open are affected by many components of reproductive management, including voluntary waiting period, estrus-detection efficiency or rate (EDR), and conception rate (CR; Barr, 1975; Esslemont, 1992; Pecsok et al., 1994a). Increases in DO reduce profitability by reducing milk yield per cow per day and availability of replacements (Oltenacu et al., 1981; Bailie, 1982). Because of its utility as a summary of overall reproduc- 
tive performance and its relationship to aspects of herd profitability, estimation of the cost of an additional DO has been frequently reported. Some authors have used direct evaluation of DHI records to estimate the cost of a DO (Speicher and Meadows, 1967; Louca and Legates, 1968; Olds et al., 1979). Other authors have used herd simulation models to attain this estimate (Dijkhuizen et al., 1985; Schmidt, 1989; Plaizier et al., 1997). The value of $\mathrm{DO}$ has been used in economic evaluations of different estrus-detection management strategies (Williamson, 1975; Mohammed et al., 1990; Britt and Gaska, 1998). The value of DO has been used in assessing the merits of pregnancy diagnosis (Oltenacu et al., 1990; Pitcher and Galligan, 1990). It has also been used in financial comparisons of herds at different overall levels of reproductive performance (Herschler et al., 1964; Esslemont, 1992; Campos et al., 1995).

As a result of the many approaches and assumptions to modeling the cost of a DO, published estimates vary, from a slightly negative cost (which implies a benefit to an additional DO), to decidedly greater positive costs. Although published estimates fall between these extremes, for the most part they imply a negative economic impact of an additional DO; a consensus exists regarding the financial consequence of inefficient reproduction. The variability in literature-based estimates of the cost of additional DO creates a challenge for veterinarians and producers when making farm-specific, cost-benefit assessments of programs that target reproductive performance. In addition, in research settings with a study objective being economic evaluation of a reproductive intervention, the value of a DO selected by researchers has a direct impact on the program's perceived utility. Thus, it has been suggested that evaluations of reproductive programs not use generalized loss estimates, and instead focus on characteristics specific to the situation under investigation (Goodger et al., 1988; Schmidt, 1989).

The objective of this paper was to describe a model that was developed to estimate the economic impact of changes in herd-level reproductive measures in Ohio dairy herds. The purpose for creating the model was to overcome limitations associated with the use of generalized loss estimates by generating situation-specific evaluations. The model was designed to allow comparison of the relative economic value of an average cow under different scenarios. Scenarios were created by entering information describing both herd characteristics and cost estimates of herd inputs as well as market value of outputs. Comparison of alternate scenarios was achieved by comparing annual cash flow per cow. Guiding principles when developing the model were to produce results consistent with other efforts while limiting complexity compared with other models.

\section{MATERIALS AND METHODS}

\section{Model Description and Development}

The model operates in Microsoft Excel 2002 (Microsoft Corporation, Redmond, WA), and on a daily basis simulates the life of an average dairy cow in a scenario, which is a set of inputs that describe herd characteristics. The inputs used in the model are detailed in the sections that follow (see Herd Description and Lactation Traits). For a given scenario, the model uses the herd characteristics to create a single average cow that represents the herd. The model has 2 important assumptions: 1) milking herd size is constant over time; and 2) an identical replacement is available when needed. Under these assumptions, estimation of the value for a single average cow provides a suitable method to compare scenarios.

For each day of the cow's life, the model estimates a partial cash flow based on expenses (of inputs) and revenues (from products) that are closely related to reproductive performance. Two sets of herd descriptions can be entered simultaneously to compare 2 scenarios. The model has 4 main sections: Herd Description, Lactation Traits, Events, and Cow Life.

\section{Herd Description}

This section allows the input of values representing herd management characteristics and values representing prices of inputs and outputs related to herd reproductive efficiency. Items that could be manipulated in the Herd Description are listed in Table 1. Factors chosen for inclusion in this model are consistent with those used in simulation-based approaches to dairy herd economic modeling (Dijkhuizen et al., 1985; Schmidt, 1989; Plaizier et al., 1997). In addition, a discount factor to adjust for differential timing of cash flows under different scenarios is entered. Herd characteristics are used in subsequent sections to define the discrete timing of events for the representative average cow.

\section{Lactation Traits}

This section assists in the generation of sets of parameter estimates for first, second, and third or greater lactation for use in Wood's equation for milk yield (Wood, 1967):

$$
\mathrm{Y}_{\mathrm{DIM}}=\mathrm{A} \times \mathrm{DIM}^{\mathrm{B}} \times \exp (-\mathrm{C} \times \mathrm{DIM})
$$

where $\mathrm{Y}_{\text {DIM }}=$ milk yield on day of lactation DIM, $\mathrm{A}=$ scaling factor related to peak milk in early lactation, B 
Table 1. List of inputs and their values used in evaluation of the baseline model.

\begin{tabular}{|c|c|}
\hline Input & Value \\
\hline \multicolumn{2}{|l|}{ Herd characteristics } \\
\hline Cull rate ${ }^{1}$ & $34 \% \mathrm{yr}$ \\
\hline Heifer calf survival to lactation ${ }^{2}$ & $80 \%$ \\
\hline Average age at first calving ${ }^{1}$ & $26.6 \mathrm{mo}$ \\
\hline Services per conception for virgin heifers ${ }^{7}$ & 2.12 \\
\hline Days to first service for cows ${ }^{1}$ & 96 \\
\hline First-service conception rate for cows ${ }^{1}$ & $45 \%$ \\
\hline Heat detection rate for cows ${ }^{1}$ & $45 \%$ \\
\hline Services per conception for all cows ${ }^{1}$ & 2.33 \\
\hline Average weight of cull $\mathrm{cow}^{3}$ & $544 \mathrm{~kg}$ \\
\hline Interest rate for alternative use of capital ${ }^{3}$ & $8 \% \mathrm{yr}$ \\
\hline \multicolumn{2}{|l|}{ Expenses } \\
\hline Cost to raise heifers ${ }^{4}$ & $\$ 1.70 / \mathrm{d}$ \\
\hline Cost of replacement heifer ready to calve ${ }^{3}$ & $\$ 1600$ \\
\hline Feed cost for dry cow maintenance ${ }^{5}$ & $\$ 1.50 / \mathrm{d}$ \\
\hline Feed cost (above maintenance) for milk ${ }^{6}$ & $\$ 0.169 / \mathrm{kg}$ \\
\hline Semen $\operatorname{cost}^{3}$ & $\$ 15 /$ service \\
\hline Additional veterinary cost, $\$ / \mathrm{d}$ & Not used \\
\hline Additional management cost, $\$ / \mathrm{d}$ & Not used \\
\hline \multicolumn{2}{|l|}{ Revenues } \\
\hline Salvage value of cull cow ${ }^{3}$ & $\$ 0.736 / \mathrm{kg}$ \\
\hline Market price of milk ${ }^{6}$ & $\$ 0.306 / \mathrm{kg}$ \\
\hline Heifer calf value ${ }^{3}$ & $\$ 200$ \\
\hline Bull calf value ${ }^{3}$ & $\$ 50$ \\
\hline
\end{tabular}

${ }^{1}$ From DHI-Plus software (Anonymous, 2004a).

${ }^{2}$ From NAHMS Dairy 2002 (USDA, 2002).

${ }^{3}$ Based on consultation with various sources.

${ }^{4}$ Gabler et al., 2000.

${ }^{5}$ Tedeschi et al., 2000.

${ }^{6}$ From Federal Milk Marketing Order \# 33 (Anonymous, 2004b).

${ }^{7}$ Donovan et al., 2003.

and $\mathrm{C}=$ shape parameters related to timing of peak and persistency of yield.

To generate parameter sets for use in Wood's equation, average values for actual 305-d milk yield as well as quantity and day of peak milk of cows in their first, second, and third or greater lactation are entered. Microsoft Excel's Solver tool is then used to generate parameter sets that minimize the difference between the entered and modeled 305-d milk yield under the constraints that the modeled peak milk and day of peak milk are within $10 \%$ of the input values. The result is that the parameter sets define lactation curves that closely match input values for $305-d$ milk, peak milk, and day of peak milk. The parameters are used later to calculate milk yield for the scenario's average cow, and values used in this report are listed in Table 2.

\section{Events}

This section establishes the specific timing of key events in the life of the average cow, such as breeding, calving, dry-off, and culling. Timing of these events for the modeled cow is calculated based on the scenario described in the Herd Description section.
First breeding and first calving. The modeled cow has a fixed age at first calving specified by the inputs. The model assumes a 280-d gestation, which was recently verified as the average gestation in a large-scale evaluation of primiparous and multiparous Holstein dairy cow records (Meyer et al., 2001). Although the inputs can indicate multiple inseminations for heifers, for simplicity the model assumes that all inseminations occur $280 \mathrm{~d}$ before first calving.

Breeding and calving for cows after first calving. The calving-to-conception interval, or DO, represents DIM at conception. Days open for the average cow are calculated using average days to first service (DFS), first-service conception rate (FSCR), EDR, and services per cow (SPcow). It is assumed that DFS, FSCR, EDR, and SPcow are the same in all lactations. It is important to use SPcow, because it accounts for all inseminations attempted in pregnant and open cows, compared with services per conception, which only accounts for inseminations made in cows that eventually become pregnant. Estimation of average DO is calculated from herd data as described below.

A proportion of cows become pregnant at first service. This proportion is equal to FSCR, and this subset of cows is assigned an average DO of DO1 = DFS. The remaining proportion of cows (1 - FSCR) is assumed to get pregnant at a rate estimated as the product of 21-d EDR and CR (Pecsok et al., 1994a). Conception rate is estimated as the inverse of SPcow. The result is a per-estrous cycle pregnancy rate (PR), which is changed to a daily PR:

$$
\mathrm{PR}_{\text {daily }}=(\mathrm{EDR} / \mathrm{SPcow}) / 21
$$

The model assumes an exponential distribution for time-to-pregnancy in cows that are not pregnant at first service. The exponential distribution is described by a single parameter (in this case $\mathrm{PR}_{\text {daily }}$ ), and the mean can be calculated quite easily as the inverse of $P R_{\text {daily }}$ (Klein and Moeschberger, 2003). Under this assumption, the mean DO for the cows not settling to first service (DO2) is

$$
\mathrm{DO} 2=\left(1 / \mathrm{PR}_{\text {daily }}\right)+\mathrm{DFS}
$$

Average DO for the herd is then estimated as:

$$
\mathrm{DO}=(\mathrm{FSCR} \times \mathrm{DO} 1)+[(1-\mathrm{FSCR}) \times \mathrm{DO} 2]
$$

This single estimate for average DO is fixed as the DIM in each lactation when the modeled cow representing the scenario becomes pregnant.

Because DO is a function of the inputs DFS, FSCR, EDR, and SPcow, different combinations of these inputs 
Table 2. Parameter sets for Wood's equation ${ }^{1}$ used in evaluation of the model. Ohio averages (Avg.) and Wood's equation predictions (Pred.) are listed for 305-d actual milk yield, peak milk, and DIM at peak.

\begin{tabular}{|c|c|c|c|c|c|c|c|c|c|}
\hline $\begin{array}{l}\text { Lactation } \\
\text { no. }\end{array}$ & \multicolumn{3}{|c|}{ Wood's equation parameters } & \multicolumn{2}{|c|}{ 305-d milk yield, $\mathrm{kg}$} & \multicolumn{2}{|c|}{ Peak milk yield, $\mathrm{kg}$} & \multicolumn{2}{|c|}{ Peak milk day, DIM } \\
\hline 2 & 11.274 & 0.411 & 0.00666 & 9068 & 9068 & 40.7 & 40.7 & 65 & 62 \\
\hline $3+$ & 10.478 & 0.447 & 0.00725 & 9218 & 9218 & 42.4 & 42.4 & 65 & 62 \\
\hline
\end{tabular}

${ }^{1}$ Equation for milk yield $\mathrm{Y}$ on DIM is: $\mathrm{Y}_{\mathrm{DIM}}=\mathrm{A} \times \mathrm{DIM}^{\mathrm{B}} \times \exp (-\mathrm{C} \times \mathrm{DIM})$.

${ }^{2}$ From DHI-Plus software (Anonymous, 2004a).

can yield the same DO. If interested only in comparing DO in different scenarios, it is possible to bypass the DO estimated by the model and specify a single DO value for each scenario. Each calving of the modeled cow is assumed to occur after a 280-d gestation (Meyer et al., 2001).

Dry-off. A 60-d dry period was used, which means that the modeled cow's lactation ends $220 \mathrm{~d}$ after conceiving at DO.

Average age at culling. In this model, the culling strategy is essentially age-based and is estimated using the age at first calving and the herd's annual culling rate. The input value for age at first calving is in months, but the model estimates daily cash flows for the average cow and needs to have age at culling in days. Therefore, the average age at culling in days is estimated using the age at first calving in months and the herd's annual culling rate:

$$
\begin{gathered}
\text { Average age at culling }= \\
(\text { age at first calving } \times 30.4) \\
+365 \text { / annual culling rate }
\end{gathered}
$$

Once the average age at culling is determined, this value is fixed as the age when the modeled cow exits the herd. Because this model focuses on a single average cow, it is not possible to specifically model a reproductive performance-related culling decision. However, scenarios with different reproductive performance and culling rates can be compared to determine the joint effect of a change in reproductive efficiency and herd turnover.

Because age at culling and other events such as calving and dry-off are fixed by the model, it is possible that a scenario will indicate an unusual herd exit time for an average cow. Age at culling is therefore adjusted in 2 special cases. First, for any scenario that indicates herd exit in the first 90 DIM, age at culling is increased so the cow is culled at 90 DIM. This is done to avoid evaluating a herd scenario in which cows (represented by the average cow) are consistently culled in early lactation. Secondly, if the scenario indicates that the cow is milked at a loss (costs of feed for maintenance and for marginal milk exceed milk revenue) in the final lactation, then age at culling is decreased so that the cow is culled on the last day that milk revenue exceeds maintenance and marginal milk feed costs. This is done to avoid evaluating a herd scenario in which cows (represented by the average cow) are consistently milked at a loss. Changing the age at culling effectively alters the culling rate that is entered. The model output indicates if the culling rate used by the model differs from the culling rate indicated in the herd description. When comparing scenarios, it is suggested that results be interpreted in light of any model-imposed changes on input culling rates.

\section{Cow Life}

This section of the model follows the life of the cow on a daily basis as described by the scenario inputs. For each day of life, the model evaluates the cow based on age relative to the timing of events described previously, and calculates expenses and revenues for factors closely related to reproductive performance. The model primarily considers expenses from herd entry and feed and semen usage, but also allows introduction of additional expenses for intensified management or veterinary treatments. An additional expense is also introduced if the scenario inputs produce less than one female offspring surviving to lactation. Revenues in the model arise from milk, calves, and salvage. Inclusion of these expenses and revenues are consistent with other dairy herd economic simulations (Dijkhuizen et al., 1985; Schmidt, 1989; Plaizier et al., 1997).

Herd entry expense. It is assumed that the average cow modeled in each scenario is born and raised in the herd, and calculation of daily cash flow begins on the first day of life. Although the cow in the scenario is not purchased as a calf, raising a calf requires that the producer forgo the opportunity to sell it at market value (an opportunity cost). This opportunity cost is charged 
against the cow at the start of life as a herd entry expense.

Daily feeding expense. For all days leading up to first calving, the model charges a daily expense for heifer rearing. Once the cow commences its first lactation, it is charged a baseline daily maintenance expense. While lactating, it is charged an additional feed expense depending on its level of milk production. When dry, it is only charged the baseline daily maintenance expense.

Veterinary and management expenses. Veterinary and management expenses can be imposed on a daily basis if necessary or desired. Often, it is preferable to use the financial comparison between scenarios without these expenses as a guide to how much can be invested in additional veterinary and management expenses to accomplish objectives in an alternate scenario.

Heifer replacement expenses. Because the model assumes that size of the milking herd remains constant, this implies that during its lifetime, the average cow needs to produce at least one female offspring that survives to first calving. If a scenario is unable to meet this requirement, the model adds a charge to purchase replacement heifers that are ready to calve. The number of female offspring that survive to first calving is determined by the average number of calves produced, the proportion of calves that are heifers, and the proportion of heifer calves that survive to first calving.

In this model, culling is age-based and dependent on the annual culling rate, and no insemination or culling decisions are made with respect to the modeled cow. Timing of these events is determined by the scenario inputs. The cow representing any scenario is allowed to produce a noninteger number of calves, which is equal to the average number of lactations completed. The average number of lactations completed is estimated using the average age at culling, the age at first calving, and the calving interval (CI). Average age at culling in days is estimated by equation [5]. The average age at first calving in months is provided as an input for the scenario. The CI in days is estimated as a 280$\mathrm{d}$ gestation period added to DO, which is either estimated by equation [4] or forced into the model. Because average age at culling and DO are in days, when calculating average number of lactations completed, the average age at first calving is converted from months to days:

Lactations completed $=$ [average age at culling

$$
-(\text { age at first calving } \times 30.4)] /(\mathrm{DO}+280)
$$

The number of female offspring surviving to first calving is determined as:
Number of females surviving to first calving =

$$
\text { (calves / 2) } \times \text { HSL }
$$

where calves $=$ the number of lactations completed by the average cow in the scenario (and half of these calves are female), and HSL = proportion of heifer calves that survive to first calving, a model input.

If a scenario indicates that the average cow lifetime produces less than one female offspring that survives to first calving, then a charge is incurred for the fraction of replacement heifer (ready to calve) cost necessary to yield one full replacement. The replacement charge, if necessary, occurs on the last day of life.

Insemination expense. At age at first conception, the cow in the model is charged an insemination expense (IE) equal to the product of SPcow for virgin heifers and semen cost.

Even though multiple inseminations likely occur (SPcow for virgin heifers is typically greater than 1), all IE are charged on a single day to simplify the calculations that are needed by the model.

In subsequent lactations, when DIM matches DO (either forced into the scenario or calculated based on DFS, FSCR, EDR, and SPcow), the model charges the cow with an IE. This is calculated as for heifers, except SPcow for cows is used instead of SPcow for virgin heifers. In addition, as with the heifer, the cow is charged with all IE on a single day to simplify the calculations needed and performed by the model.

Calf revenue. At the start of each full lactation, which is defined as a lactation followed by calving, the modeled cow is credited with revenue for a calf. It is assumed that $50 \%$ of calves are heifers, and the amount credited is equal to the average value of heifer and bull calves.

Special adjustments to calf revenue and insemination expenses. The final lactation, which is not followed by a calving, is considered incomplete, with the portion completed determined by

$$
\text { DIM at culling / }(\mathrm{DO}+280)
$$

At the start of the final incomplete lactation, the cow in the model receives fractional credit for calving, equal to the proportion defined in equation [8] of the calf revenue for a full lactation. This adjustment ensures that, during its lifetime, the average cow produces and is credited for the average number of calves indicated by the herd scenario. In addition, because the final calving is fractionally credited, the previous IE is also adjusted to a fraction (defined by equation [8]) of the IE. Furthermore, no IE is charged in the final lactation because it is not followed by a calving. Although it is recognized that many cows are actually inseminated in 
their final lactation, the use of SPcow for all cows properly accounts for the average number of inseminations made in the average lifetime of the cow.

Milk revenue. When lactating, the cow is credited with milk revenue based on milk production and the market price of milk. Milk production is calculated based on DIM and the parameters defined in the Lactation Traits section of the model. Additional feed expense beyond maintenance is calculated based on the feed cost of marginal milk and milk production.

Salvage revenue. When the cow reaches the end of herd life, it is credited with its salvage value based on average weight at salvage and market price for salvage.

Economic comparison of scenarios. Cash flow for each day of life, $\mathrm{C}_{\mathrm{d}}$, is calculated as the difference between revenues and expenses incurred on each day. Because of variation in the timing of expenses and revenues over the life of a dairy cow, it is important to use discounted cash flows in measures of economic efficiency (Stott and DeLorenzo, 1988). Therefore, for each day of life $(\mathrm{d})$, the real cash flow $\left(\mathrm{C}_{\mathrm{d}}\right)$ is discounted to its present value $\left(\mathrm{PV}_{\mathrm{d}}\right)$ at herd entry (age $\left.=1 \mathrm{~d}\right)$, using the following equation (Ross et al., 2003):

$$
\mathrm{PV}_{\mathrm{d}}=\mathrm{C}_{\mathrm{d}} /\left[(1+\mathrm{r})^{\mathrm{d}}\right]
$$

where $\mathrm{r}=$ interest rate per period (day). In the herd description, the annual discount rate $\mathrm{R}$ is entered. The daily interest rate is $R / 365$. Usually, the annual discount rate entered is a conservative rate approximating returns from alternative uses of capital.

Over the life of the cow as described by a scenario, net present value (NPV) at birth is calculated as:

$$
\mathrm{NPV}=\sum_{\mathrm{i}=1}^{\mathrm{D}} \mathrm{PV}_{\mathrm{i}}
$$

where $\mathrm{i}=$ day of life and $\mathrm{D}=$ average age of culling in days.

Although important when comparing assets with different timing of cash flows, a limitation of NPV comparisons is that they are only appropriate for comparing single lifetimes of assets (Ross et al., 2003). However, this model sensibly assumes that the dairy herd intends to continue operation in the future (the modeled cow will be replaced by an identical replacement). Thus, the modeled cow for each scenario represents a replaceable asset. When lifetimes of replaceable assets are compared, the simple NPV problem becomes a replacement chain problem (Ross et al., 2003). In the replacement chain problem, NPV comparisons are strictly limited to comparison of replaceable assets having equal life spans. In the model described here, scenarios with different annual culling rates may be defined, which leads to different herd lives and supplants the use of NPV as a suitable comparative measure between scenarios.

The replacement chain problem can be overcome by using the Equivalent Period Cost method. This method converts asset NPV to an annuity value, a constant stream of cash flows occurring during defined periods. This model converts NPV of cows in each scenario to equivalent daily cash flow (EDC) using Ross et al. (2003):

$$
\mathrm{EDC}=\mathrm{NPV} /\left\{(1 / \mathrm{r})-\left(1 /\left[\mathrm{r} \times(1+\mathrm{r})^{\mathrm{D}}\right]\right)\right\}
$$

where $\mathrm{D}=$ age at culling (in days), and $\mathrm{r}$ is the daily interest rate.

With cash flows standardized to EDC, cows under different scenarios can be compared directly without concerns for duration of herd life. An increase in EDC represents long-term value to the producer. Equivalent daily cash flow can easily be scaled to different periods such as per estrous cycle, monthly, per lactation, or annual basis with an appropriate multiplier. This is useful because most literature estimates of the value of DO are presented in terms of annual cash flow per cow (Holmann et al., 1984; Schmidt, 1989; Plaizier et al., 1997). For example, multiplying EDC by 365 allows this model to produce economic estimates in annual cash flow per cow.

\section{Model Assessment}

A set of herd descriptors was entered into the model to establish a baseline scenario representative of a typical Ohio dairy herd against which alternate scenarios were compared. Sources for the information varied and are listed in Table 1. Table 2 shows the parameter estimates used in Wood's equation for first, second, and third or greater lactations in evaluation of the model. Alternate scenarios featured changes in annual culling rates, DO, and feed and milk prices. In each evaluation, $160 \mathrm{DO}$ was forced into the model as a reference scenario, bypassing the use of DFS, FSCR, EDR, and SPcow to calculate DO. The SPcow input was used to calculate IE for cows when bred.

Effect of alternate annual culling rates and days open. To examine the joint effect of changes in annual culling rate and DO, scenarios with different annual culling rates and DO were entered into the model and compared with the baseline scenario. Equivalent daily cash flow for each scenario was scaled to equivalent annual cash flow (EAC) and comparisons between baseline and alternate scenarios were made. Comparisons were made over a range of DO from 130 to 190 , which represents a decrease or increase of 30 DO relative to Ohio's average of 160 DO, at annual 


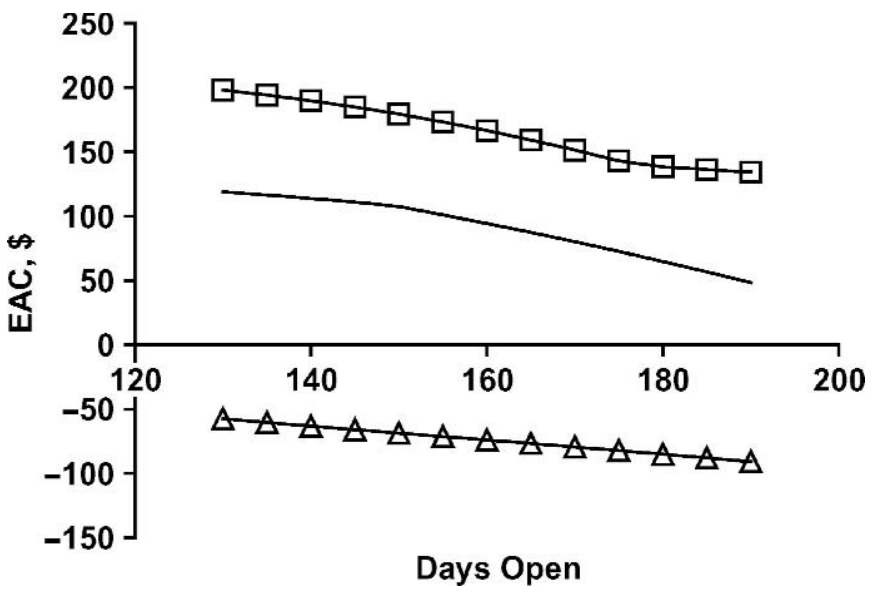

Figure 1. Effect of days open (DO) on equivalent annual cash flow (EAC) values estimated by the model for different annual culling rates: ( $\square$ ) $25 \%$ annual culling rate; (-) $34 \%$ annual culling rate, and $(\triangle) 45 \%$ annual culling rate.

culling rates of $25 \%$ (low herd turnover), $34 \%$ (Ohio average), and $45 \%$ (high turnover).

Effect of alternate days open and feed and milk prices. To examine the economic effect of alternate $\mathrm{DO}$, scenarios with different DO were entered in the model and compared with the baseline. This evaluation was performed at baseline feed and milk prices as well as for $20 \%$ increase and $20 \%$ decrease in feed and milk prices. Comparisons of milk yield and feed cost per day of life, as well as calves and mature heifers (number of female offspring surviving to first calving) produced per lifetime were made. In addition, changes in EAC relative to $160 \mathrm{DO}$ were calculated for scenarios with DO ranging from 80 to 220 . The marginal relationship between the change in EAC and DO approximates the annual cost per cow of additional DO. A marginal function is calculated as the first derivative of the function with respect to an independent variable (Binger and Hoffman, 1998). Because change in EAC vs. DO function is complex and functionally dependent on input values, the first derivative can be approximated graphically by computing the slope of the change in EAC vs. DO relationship while holding other scenario inputs fixed (Binger and Hoffman, 1998). The slope can be obtained by dividing the change in EAC by change in DO. The result is the estimated cost of a DO in terms of annual cash flow per cow.

\section{RESULTS}

Effect of alternate annual culling rates and days open. Figure 1 presents the EAC values estimated by the model for a range of DO from 130 to 190 at annual culling rates of 25,34 , or $45 \%$ and using re-

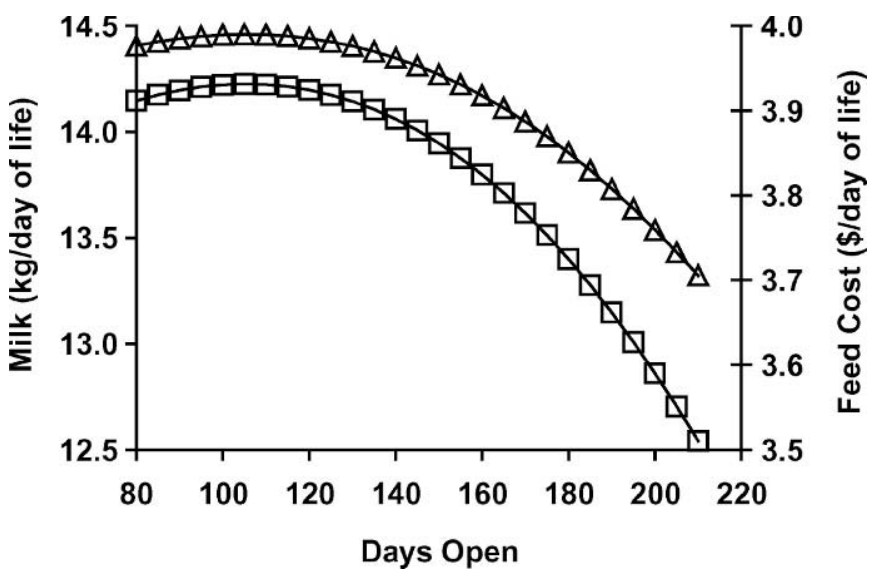

Figure 2. Effect of days open (DO) on milk yield ( $\square$ ), plotted on the left axis, and feed cost $(\triangle)$, plotted on the right axis, per day of life.

maining input values from Table 1 . At the greatest herd turnover (45\% annual culling rate), EAC is negative, suggesting that herds with high culling rates are not profitable under the input values used. In examining Figure 1, it is apparent that EAC values increase as herd turnover decreases. In addition, for a fixed annual culling rate, EAC declines as DO increase. Taken together, the preferable scenario is to have less herd turnover and shorter DO.

Effect of alternate days open and feed and milk prices. Figure 2 shows relationships of the milk yield and feed cost per day of modeled life vs. DO for the cow represented by the scenario inputs of Tables 1 and 2 . The model suggests that lifetime average daily feed costs are closely related to lifetime average daily milk yield. Figure 2 also shows that the model inputs led to maximally average daily milk yield near $110 \mathrm{DO}$, with a marked decline as DO increased.

Figure 3 shows plots of calves and mature heifers (defined by equation [7]) produced per lifetime for the modeled cow as a function of DO and the inputs from Table 1. Calves and mature heifers declined with increasing DO. The number of mature heifers produced in the modeled cow's life decreases to less than 1 as DO increase from 145 to 150 . In the modeled scenarios, the cow is charged for failure to yield one replacement. Thus, a replacement charge will appear for all scenarios based on Table 1 when DO are $>145$.

In the modeled cow, milk and calves are major sources of revenue and feed costs are the major expense. Thus, these factors should dictate the shape of the economic curves generated by the model. Figure 4 shows the model-estimated change in EAC relative to $160 \mathrm{DO}$ vs. DO for scenarios based on reference values in Tables 1 and 2 , as well as scenarios having a $20 \%$ increase or a $20 \%$ decrease in feed and milk prices. At the reference 


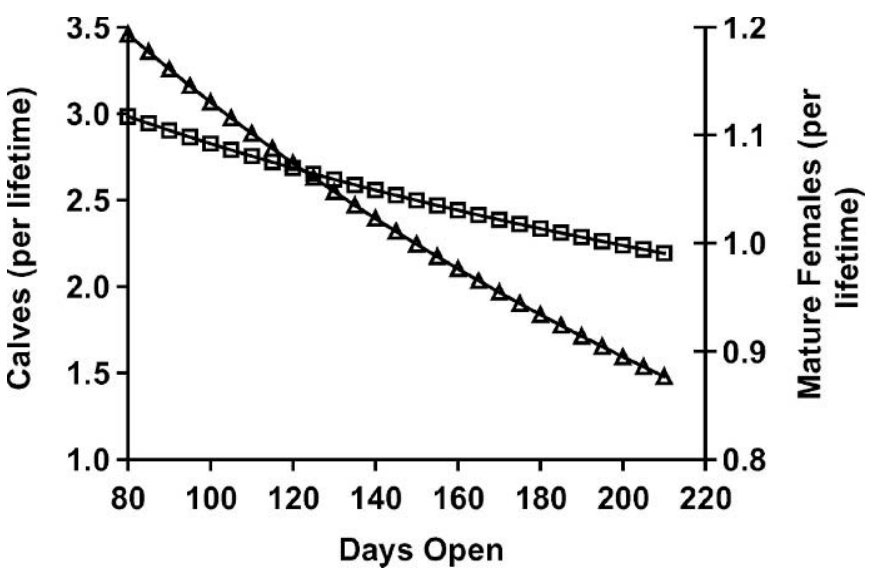

Figure 3. Effect of days open (DO) on calves produced ( $\square$ ), plotted on the left axis, and mature females produced $(\triangle)$, plotted on the right axis, per lifetime.

value of $160 \mathrm{DO}$, no change in EAC was detected. As DO decrease below 160, change in EAC was positive (EAC increases) for all milk and feed prices. Conversely, as DO increased beyond 160, EAC decreased for all milk and feed prices. At greater milk and feed prices, the increase in EAC was greater as DO decreased and the decrease in EAC (losses) was greater as DO increased.

At all 3 milk and feed price assumptions, change in EAC was not a linear function of DO, which implies that the marginal cost of additional DO is not constant and depends on DO. The marginal cost of an additional DO can be estimated as the slope of the change in EACDO relationship. The marginal cost of additional DO vs. DO for the reference values as well as for increased

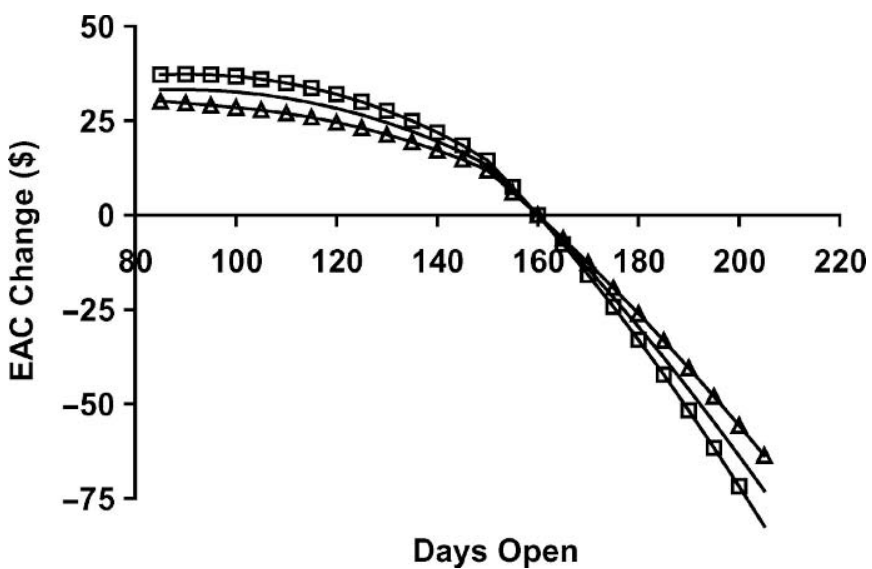

Figure 4. Effect of days open (DO) on change in equivalent annual cash flow (EAC) per cow relative to $160 \mathrm{DO}$ using reference inputs $(-)$, as well as for a $20 \%$ increase $(\square)$, and a $20 \%$ decrease $(\triangle)$ in milk and feed prices.

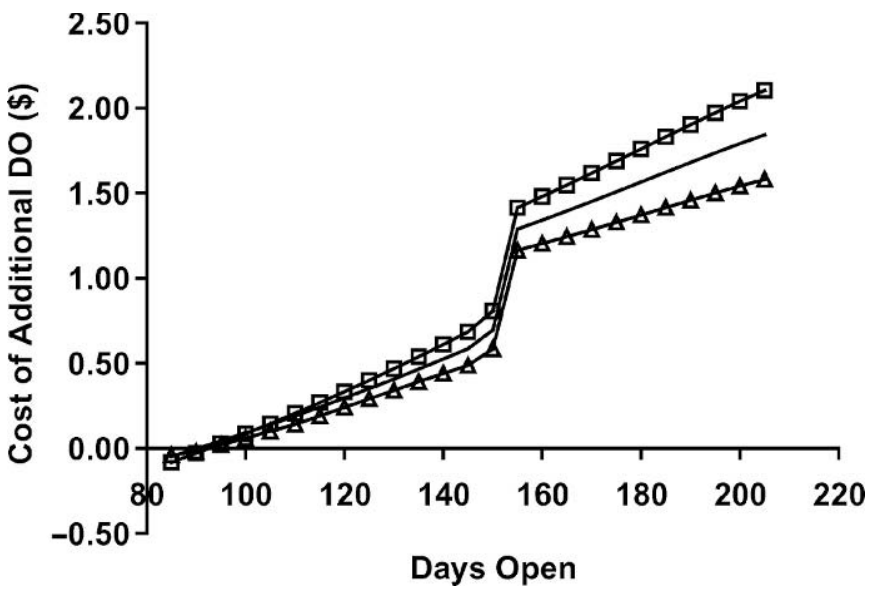

Figure 5. Effect of days open (DO) on marginal cost of an additional DO using reference inputs (-) as well as for $20 \%$ increase ( $\square$ ) or $20 \%$ decrease $(\triangle)$ in feed and milk prices.

and decreased milk prices is shown in Figure 5. The additional replacement charge that begins after 145 DO in the modeled scenarios is apparent as a brief upward turn in all 3 curves. Figure 5 indicates that a marginal DO has little cost when DO are near 95, but it becomes more costly as DO increases. In addition, estimates for marginal cost of an additional DO for different milk and feed price assumptions were similar at fewer DO, but diverged noticeably at greater DO. Marginal DO are costly as herd DO increases; greater milk and feed prices amplify this effect, whereas smaller milk and feed prices dampen this effect. Using the inputs listed in Table 1, the model approximates the cost of an additional DO at $160 \mathrm{DO}$ to be $\$ 1.37$. With a $20 \%$ increase in feed and milk prices, the model estimates $\$ 1.52$, whereas a $20 \%$ decrease in feed and milk prices leads to an estimate of $\$ 1.23$.

\section{DISCUSSION}

When using DFS, FSCR, EDR, and SPcow to estimate DO in equations [2], [3], and [4], the model makes use of the exponential distribution. An important consideration when calculating the mean for an exponential distribution is the assumption that all subjects experience the outcome. In other words, there is the assumption that all cows eventually become pregnant, which is not a perfect reflection of real dairy herds. In a 20 herd study evaluating reasons for culling, it was found that on average $20 \%$ of culls, and up to $40 \%$ of culls, were for failure to conceive (Bascom and Young, 1998). In a herd with a 35 to $40 \%$ annual culling rate, this implies that on average 7 to $8 \%$, and as many as 14 to $16 \%$ of cows fail to conceive. If it is allowed that some cows do not become pregnant and the time-to-preg- 
nancy distribution is truncated to reflect this reality, the result would be a slightly reduced estimate for mean DO. However, in this evaluation, DO estimates were forced into the model; the effect of simultaneously changing culling rate and DO was investigated and it was observed that reduced culling rates, even with more DO are generally preferable to fewer DO at greater culling rates.

Estimates of the cost of $1 \mathrm{DO}$ produced by this model are probably conservative, for at least 2 reasons. First, the model assumes that all cows are identical to the single average cow being modeled in a scenario. Because of this assumption, no increase in milk yield occurs over time due to genetic improvement. Secondly, there is no relationship between reproductive performance and culling; increased culling associated with inefficient reproduction reduces profitability (Pecsok et al., 1994b). It might be expected that culling would increase as reproductive performance declined (DO increase), adding to the cost of additional DO. The model partially accounts for large herd turnover relative to DO in that additional replacement charges occur when a scenario is unable to maintain constant herd size. However, there is not a direct relationship between DO and culling rate.

Although the model does not automatically adjust annual culling rate based on reproductive performance, the model can be used to compare the performance of scenarios with poor reproductive performance to better reproductive performance with increased culling. Culling to improve reproductive traits (such as DO and CI) has costs associated with greater culling rates (Esslemont, 1993). In addition, it has been reported that in many situations the costs associated with increased removal of cows to decrease DO exceed the benefits of reduced DO (Marsh et al., 1987). Results from the model agree with these findings-reduced herd turnover (reduced annual culling rates) yield greater EAC even at greater DO.

Based on an age at first calving of $26.6 \mathrm{mo}$ and an annual culling rate of $34 \%$, the model estimated herd life of $1883 \mathrm{~d}$ (approximately $60 \mathrm{mo}$ ) and suggested that maximal average lifetime milk yield occurred when DO $=110$. Lifetime milk yield decreased slightly as DO declined, but yield decreased more noticeably with increased DO. This is similar to the findings of Schmidt (1989), who used a 26-mo age at first calving and an agebased culling strategy of 60 mo to report that maximal lifetime milk yield occurred with a 13-mo CI (115 DO). In that study, lifetime milk yield declined little as CI decreased to $12 \mathrm{mo}$, but increased more noticeably as CI increased to 14 and 15 mo. The observation that calf and replacement heifer production declined as DO increased is not surprising, considering that the scenar- ios examined had fixed lifetimes and longer DO had the effect of reducing calving frequency in the modeled cow.

Under the inputs used in the reference example, an estimate of a cost of $\$ 1.37$ per cow per year for additional DO was obtained for the typical Ohio dairy herd, which averages $160 \mathrm{DO}$. Additional DO were found to be more costly at greater milk and feed prices, with the model estimating a cost of $\$ 1.52$ per cow per year. Reduced milk and feed prices dampened the economic effect of additional DO (\$1.23 per cow per year). Schmidt (1989) found a similar effect-losses per day associated with increased CI were more pronounced at greater milk prices.

It was also observed that the cost of a DO was not uniform-it depended on DO. At DO near 95, the estimated cost of additional DO was nearly $\$ 0$. This corresponds to the maximum of the EAC function, and implies that the optimum DO for the herd described by the inputs is 95. Assuming a 280-d gestation, the optimal CI was $375 \mathrm{~d}$, which is about 12.5 mo. These results agree with prior published guidelines (Louca and Legates, 1968; Holmann et al., 1984; Schmidt, 1989).

Estimated costs of 1 DO obtained by this model are similar to other published estimates. Earlier efforts estimating the cost of additional DO were based on analysis of DHI records. Speicher and Meadows (1967) estimated a cost of $\$ 0.78$ for additional DO beyond 117 . Louca and Legates (1968) suggested a range of $\$ 0.25$ to $\$ 0.70$ per DO. Olds et al. (1979) approximated $\$ 0.71$ for first-lactation heifers and $\$ 1.18$ for second- and greater lactation cows for each additional DO between 40 and 140. These costs are not adjusted for inflation and reflect the situation at the time of each study.

More recently, the trend has been to use computers to simulate dairy herd performance over time under different management conditions. Holmann et al. (1984) suggested a modest DO cost of $\$ 0.04$ to $\$ 0.23$ for increasing CI beyond 13 mo (120 DO). Dijkhuizen et al. (1985) estimated 2.11 Dutch guilders (about $\$ 1.16$ in 1985) per marginal DO at 165 DO. Schmidt calculated losses between $\$ 0.18$ and $\$ 0.60$ when going from a 12 mo (85 DO) to 15 -mo CI (175 DO). Plaizier et al. (1997) reported costs of $\$ 1.20, \$ 3.40$, and $\$ 5.70$ Canadian (about US $\$ 0.96, \$ 2.72$, and $\$ 4.56$ in 1997 ) for a 1 -d increase in adjusted CI (which accounts for culling of reproductive failures) at $12(85 \mathrm{DO}), 13(115 \mathrm{DO})$, and 14 mo (145 DO). Again, costs are not adjusted for inflation. Plaizier's estimates are greater than earlier estimates, but strongly reflect the joint effects of culling (by using adjusted CI) and the increasing cost of DO when reproductive efficiency declines.

Both records-based and simulation-based approaches to estimation of the cost of DO require assumptions regarding which revenues and costs will be considered; 
the market value of outputs such as milk, calves, and cull cows; costs of system inputs such as feed and semen; and herd characteristics such as heifer rearing, lactation abilities, and culling. Differences in assumptions can contribute to variability in results (Schmidt, 1989; Plaizier et al., 1997). Likewise, different assumptions can yield different estimates in the current model. This was demonstrated by showing that the estimate of the cost of DO differed as milk and feed prices were allowed to vary.

This model uses a simulation-type approach to estimate the cost of DO, but it applied some simplifying assumptions compared with other dairy herd simulation models. For any scenario, this model creates a single average cow and deterministically produces cost estimate comparisons. Because a single cow is used to represent a herd scenario, the timing of certain events such as breeding, calving, dry-off, and culling are set to occur on specific days of the average cow's life. Other dairy herd models represent more realistic herd behavior because they simulate the herd as a population of individual cows with characteristics drawn from distributions rather than averages and they allow different cows to experience events at different days in their life. Scenarios are then modeled multiple times over planning horizons and average cow values from repeated simulations are compared. These methods yield more robust results than the model described herein, but there is an increase in complexity. Such complexity is unavoidable if the modeling objective is realistic behavior (Enevoldsen et al., 1995). Our model's intent was to generate realistic results with limited complexity. In spite of the simplifications mentioned, our model was able to produce results consistent with other efforts. By producing reasonable results and having limited complexity, the current model has potential applicability in education and extension settings.

An important feature of the current model's results is the nonuniform nature of the cost of a DO. It was observed that each DO becomes more costly as DO increased. This is consistent with previous reports (Holmann et al., 1984; Dijkhuizen et al., 1985; Schmidt, 1989; Plaizier et al., 1997). This information is perhaps more useful to producers and practitioners than any single estimate of the cost of a DO. In terms of allocating limited time, labor, and capital to competing on-farm enterprises, it is important to know greater economic opportunities exist when DO are farther from a target or ideal value. Models such as ours can be used to easily illustrate and directly emphasize this important characteristic to producers.

\section{CONCLUSIONS}

Reproductive inefficiency is one of many challenges that face dairy producers as they work to maximize profitability. A relatively simple spreadsheet-based model was developed to evaluate reproductive losses in dairies in terms of the cost of DO. Results obtained with this simple model are consistent with other published estimates from more complex analyses.

At current levels of reproductive performance and price inputs, an additional DO costs the average Ohio dairy about $\$ 1.37$ in annual cash flow per cow. The loss for each additional DO increased as DO increased, suggesting that herds with extended DO have greater economic incentives to decrease DO. Conversely, as DO decreased, the financial reward for this reduction also decreased. Therefore, herds with fewer baseline DO should be more critical in evaluating the need for altering reproductive programs. The model inputs can be modified to reflect different scenarios specific to individual herds.

\section{REFERENCES}

Anonymous. 2004a. DHI-Plus for Windows. Page State Summary in Personal Herd Profile. 2.28.7 ed. DHI Computing Service, Provo, UT.

Anonymous. 2004b. Subject: Milk Market Administrator Mideast Marketing Area - Federal Order No. 33. Online. Available http:// www.fmmaclev.com/. Accessed May 6, 2004.

Bailie, J. H. 1982. Management and economic effects of different levels of oestrus detection in the dairy herd. Vet. Rec. 110:218221.

Barr, H. L. 1975. Influence of estrus detection on days open in dairy herds. J. Dairy Sci. 58:246-247.

Bascom, S. S., and A. J. Young. 1998. A summary of the reasons why farmers cull cows. J. Dairy Sci. 81:2299-2305.

Binger, B. R., and E. Hoffman. 1998. Unconstrained Maximization and Minimization. Pages 28-55 in Microeconomics with Calculus. 2nd ed. Addison-Wesley, New York, NY.

Britt, J. H. 1985. Enhanced reproduction and its economic implications. J. Dairy Sci. 68:1585-1592.

Britt, J. S., and J. Gaska. 1998. Comparison of two estrus synchronization programs in a large, confinement-housed dairy herd. JAVMA 212:210-212.

Campos, M. S., C. J. Wilcox, and T. H. Spreen. 1995. Effects of interrelationships of production and reproduction on net returns in Florida. J. Dairy Sci. 78:704-709.

Dijkhuizen, A. A., J. Stelwagen, and J. A. Renkema. 1985. Economic aspects of reproductive failure in dairy cattle. I. Financial loss at farm level. Prev. Vet. Med. 3:251-263.

Donovan, G. A., F. L. Bennett, and F. S. Springer. 2003. Factors associated with first service conception in artificially inseminated nulliparous Holstein heifers. Theriogenology 60:67-75

Enevoldsen, C., J. T. Sorensen, I. Thysen, C. Guard, and Y. T. Grohn. 1995. A diagnostic and prognostic tool for epidemiologic and economic analyses of dairy herd health management. J. Dairy Sci. 78:947-961.

Esslemont, R. J. 1992. Measuring dairy herd fertility. Vet. Rec. 131:209-212.

Esslemont, R. J. 1993. Relationship between herd calving to conception interval and culling rate for failure to conceive. Vet. Rec. 133:163-164.

Fetrow, J., D. McClary, R. Harman, K. Butcher, L. Weaver, E. Studer, J. Ehrlich, W. Etherington, W. Guterbock, D. Klingborg, J. Reneau, and N. B. Williamson. 1990. Calculating selected reproductive indices: Recommendations of the American Association of Bovine Practitioners. J. Dairy Sci. 73:78-90. 
Gabler, M. T., P. R. Tozer, and A. J. Heinrichs. 2000. Development of a cost analysis spreadsheet for calculating the costs to raise a replacement dairy heifer. J. Dairy Sci. 83:1104-1109.

Goodger, W. J., L. Weaver, J. Fetrow, and G. M. Ferguson. 1988. Development and use of an economic worksheet to assess dairy reproductive health programs. JAVMA 193:436-439.

Herschler, R. C., C. Miracle, B. Crowl, T. Dunlap, and J. W. Judy. 1964. The economic impact of a fertility control and herd management program on a dairy farm. JAVMA 145:672-676.

Holmann, F. J., C. R. Shumway, R. W. Blake, R. B. Schwart, and E. M. Sudweeks. 1984. Economic value of days open for Holstein cows of alternative milk yields with varying calving intervals. J. Dairy Sci. 67:636-643.

Klein, J. P., and M. L. Moeschberger. 2003. Common Parametric Models for Survival Data. Pages 36-45 in Survival Analysis: Techniques for Censored and Truncated Data. 2nd ed. Springer, New York, NY.

Louca, A., and J. E. Legates. 1968. Production losses in dairy cattle due to days open. J. Dairy Sci. 51:573-583.

Marsh, W. E., A. A. Dijkhuizen, and R. S. Morris. 1987. An economic comparison of four culling decision rules for reproductive failure in United States dairy herds using DairyORACLE. J. Dairy Sci. 70:1274-1280.

Meyer, C. L., P. J. Berger, J. R. Thompson, and C. G. Sattler. 2001. Genetic evaluation of Holstein sires and maternal grandsires in the United States for perinatal survival. J. Dairy Sci. 84:12461254.

Mohammed, H. O., S. Loefler, and J. Shearer. 1990. Financial comparison of three testing strategies for detection of estrus in dairy cattle. JAVMA 196:865-869.

Olds, D., T. Cooper, and F. A. Thrift. 1979. Effect of days open on economic aspects of current lactation. J. Dairy Sci. 62:1167-1170.

Oltenacu, P. A., J. D. Ferguson, and A. J. Lednor. 1990. Economic evaluation of pregnancy diagnosis in dairy cattle: A decision analysis approach. J. Dairy Sci. 73:2826-2831.

Oltenacu, P. A., T. R. Rounsaville, R. A. Milligan, and R. H. Foote. 1981. Systems analysis for designing reproductive management programs to increase production and profit in dairy herds. J. Dairy Sci. 64:2096-2104.

Pecsok, S. R., M. L. McGilliard, and R. L. Nebel. 1994a. Conception rates. 1. Derivation and estimates for effects of estrus detection on cow profitability. J. Dairy Sci. 77:3008-3015.

Pecsok, S. R., M. L. McGilliard, and R. L. Nebel. 1994b. Conception rates. 2. Economic value of unit differences in percentages of sire conception rates. J. Dairy Sci. 77:3016-3021.

Pitcher, P. M., and D. T. Galligan. 1990. Decision analysis and economic evaluation of the use of the rapid milk progesterone assay for early detection of pregnancy status of cows. JAVMA 197:1586-1590.

Plaizier, J. C., G. J. King, J. C. Dekkers, and K. Lissemore. 1997. Estimation of economic values of indices for reproductive performance in dairy herds using computer simulation. J. Dairy Sci. 80:2775-2783.

Ross, S. A., R. W. Westerfield, and J. Jaffe. 2003. Net Present Value and Capital Budgeting. Pages 169-199 in Corporate Finance. 6th ed. McGraw-Hill, New York, NY.

Schmidt, G. H. 1989. Effect of length of calving interval on income over feed and variable costs. J. Dairy Sci. 72:1605-1611.

Speicher, J. A., and C. E. Meadows. 1967. Milk production and costs associated with length of calving interval of Holstein cows. J. Dairy Sci. 50:975. (Abstr.)

Stott, A. W., and M. A. DeLorenzo. 1988. Factors influencing profitability of Jersey and Holstein lactations. J. Dairy Sci. 71:27532766.

Tedeschi, L. O., D. G. Fox, L. E. Chase, and S. J. Wang. 2000. Wholeherd optimization with the Cornell Net Carbohydrate and Protein System. I. Predicting feed biological values for diet optimization with linear programming. J. Dairy Sci. 83:2139-2148.

USDA. 2002. Highlights of NAHMS Dairy 2002: Part 1. National Animal Health Monitoring Service, Fort Collins, CO.

Williamson, N. B. 1975. The use of decision analysis to evaluate the economic effects of heat mount detectors in two dairy herds. Aust. Vet. J. 51:114-121.

Wood, P. D. P. 1967. Algebraic model of the lactation curve in cattle. Nature 216:164-165. 